\section{Royal Society helps guide Brexit science}

While the United Kingdom's relationship with the European Union is in flux, I wish to emphasize that the Royal Society's president, Venki Ramakrishnan, and its foreign secretary, Martyn Poliakoff, are more strongly engaged with Europe than ever. They are determined to continue as an effective voice for international, collaborative science (see Nature 535, 467; 2016).

Prime Minister Theresa May said she is committed to "ensuring a positive outcome for UK science as we exit the European Union". The Royal Society will work with the government to turn these words into actions and to see that the UK science community is heard in Brexit negotiations.

We have already laid the groundwork to help the country maintain its world-leading position in research and to continue attracting the best international researchers. We are also using evidence that was gathered by the Royal Society before the 23 June EU referendum to identify the best possible model of international collaboration to pursue within and beyond the EU.

Last month, our president called on the government to address post-Brexit uncertainty by underwriting the research of all UK-based scientists funded by the EU. Under \#ScienceIsGlobal, we have brought more than 30 organizations from 24 European nations together to seek assurance from their respective governments that our scientists can continue to collaborate for the benefit of society.

Julie Maxton Royal Society, London.

public.affairs@royalsociety.org

\section{Being more open about $\mathrm{PhD}$ papers}

Submitting a $\mathrm{PhD}$ thesis as a compilation of research papers can help scientists' early careers (see Nature 535, 26-28; 2016), but acknowledgements and declarations should not be overlooked along the way.

In the Netherlands, a $\mathrm{PhD}$ student's research articles - often co-authored by the supervisor - are sandwiched between introductory and concluding chapters. The thesis is published before the viva voce exam with an ISBN identifier and is later posted online. Advantages over the traditional monograph thesis include: it is quick and easy to write; feedback from the papers' reviewers can be instructive; and students attain a presence in the international science community before graduation.

I suggest that, out of courtesy, people involved in the publishing process should be informed that the papers will be assessed as part of a higher degree. They include journal reviewers and editors, as well as language professionals like me who are asked to correct the English of the manuscripts. The thesis itself could also contain a prominent statement of all assistance received, along with a declaration of the candidate's input (see B. Gustavii How to Prepare a Scientific Doctoral Dissertation Based on Research Articles; Cambridge Univ. Press, 2012). Joy Burrough-Boenisch Renkum, the Netherlands. unclogged.english@gmail.com

\section{World's last in vitro fertilization ban falls}

After a lengthy struggle, in vitro fertilization (IVF) procedures began last month in Costa Rica. This effectively ends the last full IVF ban in the world. (In countries under Islamic law, for example, IVF is permitted, albeit only within marriage.)

IVF was banned in 2000 in Costa Rica, one of the few remaining countries where Catholicism is the state religion. The ban followed pressure from religious extremists to limit women's rights and to claim full personhood for fertilized eggs (zygotes). Members of the legal, medical and scientific communities countered vigorously, for example by pointing out that a zygote remains incomplete without the developmental signals that result from implantation in the womb. Humans, after all, are not oviparous - we do not lay eggs.

The Inter-American Court of Human Rights invalidated the ban in 2012 in support of those seeking IVF treatment. However, extremist lawmakers continued to obstruct IVF until February, when the court nullified their attempts to block an executive order regulating it.

Nevertheless, the battle for women's rights in Costa Rica is far from over. For example, the country has yet to implement existing legislation that allows abortion when maternal health is compromised.

Felipe Mora-Bermúdez Max Planck Institute of Molecular Cell Biology and Genetics,

Dresden, Germany.

mora@mpi-cbg.de

\section{Stop vultures from striking aircraft}

An ecological solution is needed to prevent collisions of Eurasian griffon vultures (Gyps fulvus) with aircraft in Spain, home to some $95 \%$ of Europe's population of these large raptors. There were 26 such collisions recorded in 2006-15 around Madrid Barajas airport, which handles about 47 million passengers each year, and 3 light-aircraft strikes in the first 6 months of 2016.

This surge could be explained by the birds' relocation away from their usual feeding areas, following changes in European health regulations in 2002 (see A. Margalida et al. Nature 480, 457; 2011). Those rules forced farmers to collect and destroy livestock carcasses, an important food source for vultures.

The birds have since scavenged in areas such as landfill sites. When these are located inside air-traffic corridors (where aircraft fly below 1,200 metres), the risk of collision increases. The negative effects of the 2002 health regulations on vulture populations and demography are being tackled (see go.nature. com/2ap6zsd), but not fast enough to avert aerial collisions.

To manage the situation more effectively, we need a better understanding of the movement ecology of vultures around sensitive areas, the spatial distribution of their food resources and a warning system that detects vultures entering air-traffic corridors.

Antoni Margalida University of Lleida, Spain. amargalida@ca.udl.cat

\section{Music calculations out of tune}

It is perhaps not surprising that the Tsimane' villagers in Bolivia cannot tell the difference between minor and major keys, or dissonant and non-dissonant sounds (Nature 535, 199-200; 2016). Alternative musical scales and intervals have been known to musicians for centuries - for example, they often account for the varying timbres of different folk music (see also go.nature. com/2avI1fn).

Your assertion that "consonant intervals ... are integral ratios of harmonics - 2:1, 4:3 and $3: 2$ " is out of tune. Except for octaves (2:1), this has not been true in Western music since at least Bach's time. The title of his famous collection of fugues, 'The Well-Tempered Clavier', does not allude to his clavier's behaviour. All modern pianos, and therefore modern Western music, are in fact equal-tempered, such that the increase in frequency per semitone is $2^{1 / 12}$ - that is, about 1.059 (see go.nature.com/2aazsvs). For each key from $\mathrm{C}$ major to $\mathrm{B}$ minor, the perfect fifth is not a ratio of 1:1.5, but 1:1.498.

Adrian Goldman University of Leeds, UK.

a.goldman@leeds.ac.uk 